\title{
Acaricidal activities of some essential and fixed oils on the two-spotted spider mite, Tetranychus urticae
}

\author{
Manal S. M. Ismail ${ }^{1}$, Mona M. A. Ghallab ${ }^{1}$, Maha F. M. Soliman ${ }^{2}$ and \\ Ahmed H. AboGhalia ${ }^{2}$ \\ 1- Plant Protection Research Institute, Agriculture Research Center, Dokki, \\ Cairo, Egypt. \\ 2- Zoology Department, Faculty of Science, Suez Canal University, Ismailia, \\ Egypt \\ Corresponding author: manal_sayed99@hotmail.com
}

\section{ABSTRACT}

A comparison was made for studying the effect of some Essential oils: Rosemary, Garlic, Jojoba and Fixed/Vegetable oils on the important mite pest, Tetranychus urticae. The sublethal concentrations of Rosemary oil $(0.125 \%)$, Garlic oil $(0.5 \%)$, Jojoba oil $(0.25 \%)$ and Vegetable oil $(0.125 \%)$ were used. Biological tests were carried out for a susceptible laboratory two-spotted spider mites strain reared under controlled conditions of $27 \pm r^{\circ} \mathrm{C} ; 60 \%$ R.H. and 16L/8D photoperiod on Sweet Potato leaves. Results showed that Garlic oil caused the highest significant decrease in the number of deposited eggs as compared to the other tested oils. All the oils used have no effects on females mite fertility. Vegetable oil greatly affected the percentage of nymphs that reached adult stages followed by Jojoba oil then Garlic oil while Rosemary had no effects on nymph's developments. Results were tabulated, analyzed, discussed and prepared to be fit in any IPM program for combating these pest animals.

Key words: Tetranychus urticae, Acaricidal activities, Essential oils, Fixed oil

\section{INTRODUCTION}

A well known fact is that members of the Acarid family (Tetranychidae), contains more than 1,200 polyphagous mite pest species and Tetranychus urticae Koch (TSSM) might be considered the most important one (Alzoubi and Cobanoglu, 2008). It attacks over 300 host plants including vegetables (e.g., beans, eggplant, peppers, tomatoes, and potatoes), fruits (e.g., strawberries, raspberries, currants, and pear) and ornamentals plants (Le Goff et al., 2009). Defoliation, leaf burning, and even plant death can occur due to direct feeding damage. Indirect effects of feeding may include decreases in photosynthesis, transpiration and can lead to yellow to white discoloration of the leaf often referred to as bronzing, causing loss of quality and yield or the death of the host plants (Park and Lee, 2002).

Unfortunately, members of this mite pest have been found to be resistant against chemicals. Reasons for this may be their short developmental period and high fecundity enforced by life-history characteristics to produce successive generations. Hence, a real need is an obligation to find other approaches that capitalize on safe natural products. Natural products are excellent alternative to synthetic pesticides, as a mean to reduce negative impacts to human health and the environment. They are more compatible with the environmental components than synthetic pesticides. At 
presents, the plant derived essential oils are attracting interests of the scientists, as these are environmentally safe and non-toxic to human (Isman and Machial, 2006).

Many plant-derived essential oils like Rosemary, Garlic, Jojoba and other Vegetable/Fixed oils have insecticidal and miticidal properties, with a broad-spectrum of activity against many different types of soft-bodied arthropod pests (Alexenizer and Dorn, 2007). This is mainly due to having multiple modes of action, including antifeedant and repellent activity, molting, and respiration inhibition, growth, and fecundity reduction, cuticle disruption, and activity on the octopamine pathway in the central nervous system (Akhtar and Isman, 2004).

Under natural conditions, organisms are subject to a combination of environmental factors, both biotic and abiotic. It is this combination that ultimately determines the distribution and abundance of a species. The relationship between temperature and insecticide toxicity in insects has been studied widely. Although this phenomenon has been examined extensively in many insect species, few studies have compared the responses of insecticide susceptible with insecticide-resistant strains at different temperatures (Nabeta et al., 2005).

Our research goals were to study the efficacy of some plant-derived essential oils and Vegetable/Fixed oils in controlling the two-spotted spider mite and to determine how they would affect the reproductive rates, under laboratory conditions.

\section{MATERIALS AND METHODS}

\section{Rearing of two-spotted spider mite strain}

The two-spotted spider mites were collected from infested leaves of the Castor bean trees grown in the experimental farm of Ismailia agriculture research station. The adult females of mites were transferred with a brush to disks of Sweet Potato leaves kept on moist cotton wool pads in Petri-dishes for $24 \mathrm{hr}$. The deposited eggs were kept under constant temperature of $27 \pm 0.5^{\circ} \mathrm{C} ; 60 \%$ R.H. and $(16 \mathrm{~L} / 8 \mathrm{D})$ photoperiod until hatching. The newly hatched larvae were then transferred to fresh leaves. Sweet Potato cutting holding about 8 leaves each was placed in glass jars containing tap water which was changed every $48 \mathrm{hr}$. The sweet potato cuttings were changed twice a week in summer and weekly in winter. The colony was bred in a climatically controlled room at $27 \pm 2^{\circ} \mathrm{C} ; 60 \%$ R.H. and (16 L: $\left.8 \mathrm{D}\right)$ photoperiod for one year (Yousri, 1987).

\section{The compounds used}

\section{A. Essential oils:}

\section{Rosemary oil}

Rosemary oil is extracted from Rosmarinus officinalis of the Labiatae family. Pure essential oil (Intarome TO, 1OT\#0213142mb-100\%) was obtained from EcoSMART Technologies Inc. (Franklin, TN, USA). There are 10 major constituents in the oil which are Camphene, 1,8-Cineole, $\alpha$-Pinene, $\beta$-Pinene, Camphor, $\rho$ Cymene, Borneol and D-Limonene, $\alpha$-Terpineol, Bornyl acetate (Miresmailli et al., 2006).

\section{Garlic oil}

Garlic oil is extracted from Allium sativum of the Alliaceae family. Pure essential oil was obtained from El Masry Co. for essential oil extracts. Its constituents are: Alliin $\left(\mathrm{C}_{6} \mathrm{H}_{11} \mathrm{O}_{3} \mathrm{~S}\right)$ and Allicin $\left(\mathrm{C}_{6} \mathrm{H}_{10} \mathrm{OS}_{2}\right)($ Ogara et al., 2000).

\section{Jojoba oil}

Jojoba oil is extracted from the jojoba tree Simmondsia chinenis of the Simmondsiaceae family. Pure essential oil was obtained from Egyptian Natural Oil 
Co. (NATOIL), Egypt. Jojoba oil is a mixture of wax esters, 36 to 46 carbon atoms in length. Each molecule consists of a fatty acid and a fatty alcohol joined by an ester bond, $98 \%$ of the fatty acid molecules are unsaturated at the $9^{\text {th }}$ carbon-carbon bond (omega-9) (Wikipedia, 2011a).

\section{A. Fixed oil (Vegetable oil 75\%)}

Vegetable oil is composed of mixture of Soybean \& Sunflower oils $(50 \%+50 \%=$ 1:1). This emulsion was obtained from Egyptian Salt \& Soda Co. Egypt. Soybean oil is a vegetable oil extracted from the seeds of the soybean (Glycine max) while Sunflower oil (non-volatile oil) expressed from sunflower Helianthus annuus seeds. It contains predominantly linoleic acid in triglyceride form. It also contains lecithin, tocopherols, carotenoids and waxes (Wikipedia, 2011b).

\section{Adulticide bioassay}

\section{Calculating the $\mathrm{LC}_{50}$ of tested compounds}

Five serially diluted concentrations covering the range of 0 to $100 \%$ mortality were used and 5 replicates per concentration were prepared to calculate the $\mathrm{LC}_{50}$ of the essential oils and the fixed oils used. Series of aqueous concentrations of essential oils were prepared using Triton X-100 as surfactant at rate $0.1 \%$ and Triton X-100 alone was used as a control treatment (Koscheir et al., 2002). According to the method of Mailloux and Morrison (1962), discs of Sweet Potato leaves (1 inch in diameter) were placed in Petri-dishes lined with water-saturated cotton wool. The cotton should be wet to avoid migration of the mites to the lower leaf surface. With the aid of a binocular-microscope and with a fine paintbrush, 60 adult females mite were introduced on the lower surface of the discs in triplicates per treatment. Each Petri-dish was sprayed with a constant amount of the tested solutions for 5 seconds using a glass manual atomizer (Sigma glass spray unit No. S 3135). They were left to dry for $30 \mathrm{~min}$, then subsequently placed in a climatically controlled room at $27 \pm 2^{\circ} \mathrm{C}$; 60\% R.H. and (16L: 8D) photoperiod (Yousri, 1987). The survivors were counted after $24 \mathrm{hr}$ and the mean mortality rates were calculated.

\section{Evaluation of female mite mortality, fecundity, fertility and offspring development at $27 \pm 2^{\circ} \mathrm{C}$}

One sublethal concentration for each oil was used $(0.125 \%),(0.5 \%),(0.25 \%)$ and $(0.125 \%)$ for Rosemary, Garlic, Jojoba and Vegetable oils, respectively. Discs of Sweet Potato leaves ( 1 inch in diameter) were dipped in the tested solutions and gently agitated for 5 seconds, then gently blotted to remove excess liquid and allowed to dry for 30-45 min. then placed in Petri-dishes with water-saturated cotton wool in triplicates per treatment. Control individuals were sprayed with Triton X-100.

With the aid of a binocular-microscope, 20 quiescent female deutonymphs (after mating) were transferred using fine paintbrush to the lower surface of leaf discs and were allowed to deposit eggs for 4 days. All Petri-dishes were then placed under constant temperature at $27 \pm 2^{\circ} \mathrm{C} ; 60 \%$ R.H. and $(16 \mathrm{~L} / 8 \mathrm{D})$ photoperiod. After 4 days, numbers of alive females and laided eggs were monitored (Marčić et al., 2009). All females were then removed and the survivors were counted, then the mean mortality rates were calculated. Daily observations with a stereomicroscope were made during the incubation period up to emergence of the larvae and after eclosion of the larvae till adulthood, to determine the developmental periods (Silva et al., 2009).

\section{Statistical analysis}

All data concerning mortality, fertility and hatchability rates were presented as arithmetic means $( \pm \mathrm{SE})$. For studying differences between groups, data were analyzed by student t-test or analysis of variance (ANOVA). All the statistical tests were performed by using the software packages SPSS 15.0.0 (USA). 


\section{RESULTS AND DISCUSSION}

The $\mathrm{LC}_{50}$ value of Rosemary, Garlic, Jojoba and Vegetable oils predicted by Probit analysis for adult females $24 \mathrm{hr}$ post-treatment were $0.6,2.1,1.5$, and $0.8 \%$, respectively.

The present study showed that the $\mathrm{LC}_{50}$ of Rosemary oil was $0.6 \%$., this value was lower than that reported by Miresmailli et al. (2006) who recorded the $\mathrm{LC}_{50}$ of Rosemary oil as $1 \%$ for adult female spider mites reared on bean plants and $1.3 \%$ for those reared on tomato plants. Miresmailli (2001), by using the leaf disc painting method, recorded the $\mathrm{LC}_{50}$ of pure rosemary oil as $1.3 \%$, Hexacide (containing $5 \%$ rosemary oil) as $0.4 \%$, EcoTrol (containing $10 \%$ rosemary oil) as $0.6 \%$ and Sporan (containing $18 \%$ rosemary oil) as $1.1 \%$ for spider mites.

The $\mathrm{LC}_{50}$ of Garlic oil was $2.1 \%$. Hincapié et al. (2008) compares different extracts from Garlic (A. sativum L.) bulbs measuring their toxicity and repellency effects on T. urticae. They reported that Garlic extract which extracted by different techniques of extraction from Garlic bulbs showed different acaricide activity against T. urticae.

The $\mathrm{LC}_{50}$ of Jojoba oil was $1.5 \%$. El-Duweini and Sedrak (1997) studied the efficacy of Jojoba oil against different stages of the phytophagous mite T. arabicus, and the adult female of the predaceous mite Euseius scutalis. They found that, the $\mathrm{LC}_{50}$ and $\mathrm{LC}_{90}$ for T. arabicus larvae, deutonymphs, adult females and eggs were 0.53 $\& 4.28,1.21 \& 5.17,1.60 \& 6.35$, and $2.53 \& 10.86$, respectively. The present study data showed that the $\mathrm{LC}_{50}$ of Vegetable oil was $0.8 \%$. No previous records for the $\mathrm{LC}_{50}$ of this oil.

Rosemary oil obtained results showed the lowest $\mathrm{LC}_{50}$ against $T$. urticae under laboratory conditions in comparison to the other extracts while Garlic oil showed the highest $\mathrm{LC}_{50}$. However, the differences between $\mathrm{LC}_{50}$ for the oils examined in this study and other studies may be due to the formulation of the oils, the strain of TSSM, laboratory condition and extraction methods. In this regards, Hincapié et al. (2008) reported that garlic extract which extracted by different techniques of extraction from garlic bulbs showed different acaricide activity against $T$. urticae.

Regarding the acaricidal effect of Rosemary oil on TSSM 4 days posttreatment at $27 \pm 2^{\circ} \mathrm{C}$, results showed that no mortality was recorded using the sublethal concentration as shown in Table (1). Fecundity, fertility and hatchability rates in the $1^{\text {st }}, 2^{\text {nd }}$ and $3^{\text {rd }}$ day post hatching, $\%$ of larvae developed to nymphs and $\%$ of nymphs developed to adults were $5.9 \pm 0.6 \%, 99.1 \pm 0.2 \%, 34.9 \pm 2.9 \%, 27.9 \pm 1.5 \%, 37.1 \pm 2.2 \%$, $97.9 \pm 0.7 \%$, and $90 \pm 1.2 \%$, respectively (Table 1 ). In addition, developmental period of TSSM completed in about 9 days against 11 days in control as shown in Table (2).

Miresmailli and Isman (2006) and Miresmailli et al. (2006) clearly indicate that Rosemary oil can be considered as an acaricide against TSSM, causing complete mortality in the laboratory at concentration that cause no phytotoxicity to host plants and can affect oviposition behavior. Moreover, another important characteristic of Rosemary oil is its complex chemical composition; it is a mixture of terpenoids. Complete mortality $(100 \%)$ of mites was obtained with a $2 \%$ concentration of the oil on Bean plants and $4 \%$ on Tomato plants in greenhouses.

According to Miresmailli (2001), Rosemary oil was found to be more toxic to spider mites as a contact toxicant while it was more effective against whiteflies as fumigant. Differences between the present results and that of Miresmailli and Isman (2006); Miresmailli et al. (2006) and Miresmailli et al. (2001) may be attributed to different concentrations used and the method they adopt for a low concentration of 
Rosemary oil. Choi et al. (2004) evaluated the toxicity of 53 essential oils including Rosemary against eggs and adults of two-spotted spider mites as fumigant. Rosemary oil was not very toxic (mortality $<60 \%$ ) comparing to Caraway seed, Citronella java, Lemon, Eucalyptus, Pennyroyal and Peppermint oil, which were highly toxic (mortality $>90 \%$ ) to the tested mites. Our results clearly indicate that Rosemary oil based pesticides are not environmentally persistent. In all experiments, toxicity of residues significantly declined after $24 \mathrm{hr}$. All these conflicting results indicate that Rosemary oil activity may be affected by its volatilization, concentration and technique used.

Table 1: Fecundity, fertility and offspring developments of T. urticae adult females (4 day posttreatment) treated with sublethal concentrations of Rosemary oil $(0.125 \%)$, Garlic oil $(0.5 \%)$, Jojoba oil $(0.25 \%)$ and Vegetable oil $(0.125 \%)$ at $27 \pm 2^{\circ} \mathrm{C}(\mathrm{n}=20$ females).

\begin{tabular}{|c|c|c|c|c|c|c|c|}
\hline \multicolumn{3}{|l|}{ Parameters } & & & & & \\
\hline & \multicolumn{2}{|c|}{ Treatments } & Control & Rosemary oil & Garlic oil & Jojoba oil & Vegetable oil \\
\hline \multicolumn{3}{|c|}{ Mean mortality \% } & 0.0 & 0.0 & 0.0 & 0.0 & 0.0 \\
\hline \multirow[t]{2}{*}{$\begin{array}{l}\text { No. of eggs deposited } \\
\text { (Fecundity) }\end{array}$} & \multicolumn{2}{|c|}{$\begin{array}{l}\text { Mean no. of eggs } / 60 \\
\text { female }\end{array}$} & $560 \pm 11.5$ & $351.3 \pm 35$ & $221.3 \pm 11$ & $347 \pm 31$ & $356 \pm 32$ \\
\hline & \multicolumn{2}{|c|}{ Mean no. of eggs/female } & $9.3 \pm 0.2$ & $5.9 \pm 0.6$ & $3.7 \pm 0.2$ & $5.8 \pm 0.5$ & $5.9 \pm 0.5$ \\
\hline \multirow{8}{*}{ 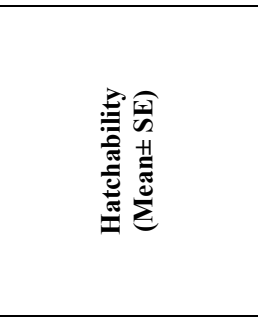 } & \multirow{2}{*}{ First day } & No. & $306.7 \pm 18.9$ & $123.3 \pm 22$ & $89.6 \pm 2.9$ & $193 \pm 22.6$ & $144.3 \pm 14.3$ \\
\hline & & $\%$ & $54.9 \pm 2.9$ & $34.9 \pm 2.9$ & $41 \pm 2.01$ & $56.8 \pm 2$ & $40.9 \pm 2.1$ \\
\hline & \multirow{2}{*}{ Second day } & No. & $182.3 \pm 11.4$ & $96.3 \pm 4.4$ & $123.7 \pm 9.3$ & $125.7 \pm 13.4$ & $110 \pm 42.3$ \\
\hline & & $\%$ & $32.6 \pm 1.4$ & $27.9 \pm 1.5$ & $56 . \Upsilon \pm 1.8$ & $37.1 \pm 5.2$ & $29.9 \pm 9.4$ \\
\hline & \multirow{2}{*}{ Third day } & No. & $68.3 \pm 15.9$ & $128.7 \pm 11.9$ & $6 \pm 1.2$ & $19.7 \pm^{0} . \mathrm{r}$ & $9 \Lambda . r \pm Y r . \Lambda$ \\
\hline & & $\%$ & $12.3 \pm 3.1$ & $37.1 \pm 2.2$ & 2. $\vee \pm 0.4$ & $6.1 \pm 2.12$ & $29.1 \pm 8.1$ \\
\hline & \multirow{2}{*}{$\begin{array}{l}\text { Hatched eggs } \\
\text { (Fertility) }\end{array}$} & No. & $557.3 \pm 11.3$ & $348.3 \pm 35.4$ & $219.3 \pm 11.2$ & $338.3 \pm 29.1$ & $352.7 \pm 31.1$ \\
\hline & & $\%$ & $99.5 \pm 0.2$ & $99.1 \pm 0.2$ & $99.1 \pm 0.3$ & $97.6 \pm 0.9$ & $99.1 \pm 0.2$ \\
\hline \multirow{2}{*}{\multicolumn{2}{|c|}{$\begin{array}{c}\text { Larvae developed to nymphs } \\
(\text { Mean } \pm \text { SE) }\end{array}$}} & No. & $546.7 \pm 13.1$ & $341 \pm 34.7$ & $206.7 \pm 12.8$ & $303.7 \pm 24.8$ & $327 \pm 32.6$ \\
\hline & & $\%$ & $98.1 \pm 0.5$ & $97.9 \pm 0.7$ & $94.2 \pm 2.4$ & $89.8 \pm 1.02$ & $92.5 \pm 1.5$ \\
\hline \multirow{2}{*}{\multicolumn{2}{|c|}{$\begin{array}{c}\text { Nymphs developed to adults } \\
(\text { Mean } \pm \text { SE) }\end{array}$}} & No & $535.3 \pm 15.4$ & $307 \pm 31.8$ & $5.3 \pm 0.3$ & $3.33 \pm 0.3$ & $1.3 \pm 0.3$ \\
\hline & & $\%$ & $97.9 \pm 0.6$ & $90 \pm 1.2$ & $2.6 \pm 0.3$ & $1.1 \pm 0.2$ & $0.4 \pm 0.2$ \\
\hline
\end{tabular}

Table 2: Offspring development of T. urticae treated with sublethal concentrations of Rosemary oil $(0.125 \%)$, Garlic oil $(0.5 \%)$, Jojoba oil $(0.25 \%)$ and Vegetable oil $(0.125 \%)$ at $27 \pm 2^{\circ} \mathrm{C}(\mathrm{n}=20$ females).

\begin{tabular}{|c|c|c|c|c|c|c|}
\hline \multicolumn{2}{|l|}{ Parameters } & Control & Rosemary oil & Garlic oil & Jojoba oil & Vegetable oil \\
\hline & Treatments & & & & 2 & 2 \\
\cline { 2 - 7 } & Egg to larva & 4 & 1 & 1 & 1 & 6 \\
\hline & Larva to nymph & 1 & 6 & 6 & 6 & 9 \\
\hline & Nymph to adult & 6 & 9 & 3 & 3 & 0.0 \\
\hline
\end{tabular}

Regarding to Miresmailli and Isman (2006) choice tests results, Rosemary oil is significantly repellent to the two-spotted spider mite. It repelled mites for $\approx 6 \mathrm{hr}$ and then mites gradually started to move toward treated discs. However, mites preferred untreated leaves for oviposition. Repellent effects of Rosemary oil cannot be considered as a stand-alone control method, but they can be combined with other methods to improve pest management strategies.

Momen et al. (2001) studied the deterrent and toxic effect of $R$. officinalis on the two tetranychid mites T. urticae Koch and E. orientalis Klein under laboratory conditions. Leaf discs treated with increasing concentrations of the two oils showed increased mortality of both spider mites and reduction in the total numbers of laying 
eggs. These results could be due to the oil of the higher oxygenated compounds content that was more effective in this respect. Little is known about the exact site of action of Rosemary oil and other plant essential oils on the two-spotted spider mites. The octopaminergic nervous system is considered to be the site of action of essential oils in the American cockroach (Enan, 2001), but this may not be the case for the twospotted spider mite and there is the possibility that the essential oils have more than one site of action since they are complex mixtures.

Regarding the acaricidal effect of Garlic oil on TSSM 4 days post-treatment at $27 \pm 2^{\circ} \mathrm{C}$, results showed that no mortality was recorded using the sublethal concentration as shown in Table (1). Fecundity, fertility and hatchability rates in the $1^{\text {st }}, 2^{\text {nd }}$ and $3^{\text {rd }}$ day post hatching, $\%$ of larvae developed to nymphs and $\%$ of nymphs developed to adults were $3.7 \pm 0.2 \%, 99.1 \pm 0.3 \%, 41 \pm 2.01 \%, 56.2 \pm 1.8 \%, 2.7 \pm 0.4 \%$, $94.2 \pm 2.4 \%$ and $2.6 \pm 0.3 \%$, respectively (Table 1 ). In addition, developmental period of TSSM was around 11 days (the same as control as shown in, Table 2).

As to the acaricidal effect of Jojoba oil on TSSM 4 days post-treatment at $27 \pm 2^{\circ} \mathrm{C}$, results showed that no mortality was recorded using the sublethal concentration as shown in Table (1). Fecundity, fertility and hatchability rate in the $1^{\text {st }}, 2^{\text {nd }}$ and $3^{\text {rd }}$ day post hatching, $\%$ of larvae developed to nymphs and $\%$ of nymphs developed to adults were $5.8 \pm 0.5 \%, 97.6 \pm 0.9 \%, 56.8 \pm 2 \%, 37.1 \pm 5.2 \%, 6.1 \pm 2.12 \%$, $89.8 \pm 1.02 \%$ and $1.1 \pm 0.2 \%$, respectively (Table 1 ). In addition, developmental period of TSSM was about 9 days against 11 days in control as shown in Table (2). Ghoneim et al. (2007) investigate the effects of Jojoba oil on the reproductive potential of Musca domestica. They found that Jojoba exhibited only a slight effect on both fecundity and fertility. Different doses of Jojoba $(0.1,1,10,50,100$ and $500 \mu \mathrm{g} / \mathrm{larva})$ had been topically applied onto the late third instar larvae of $M$. domestica. The smallest fecundity $(171.8 \pm 24.5$ vs $231.3 \pm 23.6 \mathrm{eggs} / \%$ of controls $)$ was attained at the highest dose, while the smallest fertility ( 81.0 vs $88.3 \%$ of control congeners) was found at the lowest dose. Marei et al. (2009) evaluate the effect of Jojoba oil on biological, physiological as well as biochemical changes of the cotton leaf worm Spodoptera littoralis Boisd. They found that Jojoba oil extracts caused pronounced prolongation in both larval and pupal duration and cause pupal mortality (50\%) at 3\% concentration. The mode of action and the reason for Jojoba oil specificity are not totally understood.

As to the acaricidal effect of Vegetable oil on TSSM 4 days post-treatment, at the normal temperature $27 \pm 2^{\circ} \mathrm{C}$, results showed that no mortality was recorded using the sublethal concentration as shown in Table (1). Fecundity, fertility and hatchability rate in the $1^{\text {st }}, 2^{\text {nd }}$ and $3^{\text {rd }}$ day post hatching, $\%$ of larvae developed to nymphs and $\%$ of nymphs developed to adults were $5.9 \pm 0.5 \%, 99.1 \pm 0.2 \%, 40.9 \pm 2.1 \%, 29.9 \pm 9.4 \%$, $29.1 \pm 8.1 \%, \quad 92.5 \pm 1.5 \%$ and $0.4 \pm 0.2 \%$, respectively (Table 1). In addition, developmental period of TSSM was about 9 days against 11 days in control as shown in Table (2). Park et al. (2008) developed an organic control method of TSSM by using cooking/vegetable oil and yolk mixture (COY) through evaluating their acaricidal activities in laboratory and green house. In lab, there was no significant difference in acaricidal activity against $T$. urticae within the COY including Soybean, Canola, Sunflower and Olive oil. The acaricidal activity against T. urticae increased from $17.6 \%$ to $94 \%$ as the COY became concentrated between $0.1 \%$ to $1 \%$. The COY acaricidal activity was affected by the quantity of treatment according to application methods. The COY dealt with T. urticae eggs presented $95 \%$ of the ovicidal activity. In Rose greenhouse damaged by $T$. urticae, the COY $(0.3 \%)$ was sprayed three times and resulted in the high control value of mites between $69.0 \%$ to $89.6 \%$. 


\section{REFERENCES}

Akhtar, Y. and Isman, M.B. (2004): Comparative growth inhibitory and antifeedant effects of plant extracts and pure allelochemicals on four phytophagous insect species. J. Appl. Entomol., 128: 32-38.

Alexenizer, M. and Dorn, A. (2007): Screening of medicinal and ornamental plants for insecticidal and growth regulating activity. J. Pest Sci., 80: 205-215.

Alzoubi, S. and Cobanoglu, S. (2008): Toxicity of some pesticides against Tetranychus urticae Koch and its predatory mites under laboratory conditions. AmericanEurasian J. Agric. Environm. Sci., 3(1): 30-37.

Choi, W.; Lee, S.; Park, H. and Ahn, Y. (2004): Toxicity of plant essential oils to Tetranychus urticae (Acari: Tetranychidae) and Phytoseiulus persimilis (Acari: Phytoseiidae). J. Econ. Entomol., 97: 553-558.

El-Duweini, F.K. and Sedrak, R.A. (1997): Evaluation of Jojoba oil for control of spider mite (Acari: Tetranychidae) in Egypt. Beltwide Cotton Conferences, 2: 10601063.

Enan, E. (2001): Insecticidal activity of essential oils: octopaminergic sites of action. Comp. Biochem. Physiol. C. Toxicol. Pharmacol., 130: 325-337.

Ghoneim, K.S.; Amer, M.S.; Bream, A.S.; Al-Dali, A.G. and Hamadah, Kh.Sh. (2007): Effectiveness of Margosan-O and Jojoba on some reproductive aspects of the house fly, Musca domestica (Diptera: Muscidae). Int. J. Agri. Biol., 9(2):338-341.

Hincapié, C.A.; López, G.E. and Torres, Y.R. (2008): Comparison and characterization of Garlic (Allium sativum L.) bulbs extracts and their effects on mortality and repellency of Tetranychus urticae koch (Acari: Tetranychidae). Chilean J. Agric. Res., 68(4): 317-327.

Isman, M.B. and Machial, C.M. (2006): Pesticides based on plant essential oils: from traditional practice to commercialization. In M. Rai and M.C. Carpinella (eds.), Naturally Occurring Bioactive Compounds, Elsevier, BV, pp 29-44.

Koschier, E.H.; Sedy, K.A. and Novak, J. (2002): Influence of plant volatiles on feeding damage caused by the Onion Thrips Thrips tabaci. Crop Prot., 21: 419-425.

Le Goff, G.; Mailleux, A.C.; Detrain, C.; Deneubourg, J.L.; Clotuche, G. and Hance, T. (2009): Spatial distribution and inbreeding in Tetranychus urticae. Biologies, 332: 927-933.

Mahmoud, M.F.; Osman, M.A.; Bahgat, I.M. and El-Kady, G.A. (2009): Efficiency of Spinetoram as a biopesticide to Onion Thrips (Thrips tabaci Lindeman) and Green Peach Aphid (Myzus persicae Sulzer) under laboratory and field conditions. J. Biopestic., 2(2): 223-227.

Mailloux, M. and Morrison, F.O. (1962): The effect of acaricides on developmental stages of the two-spotted spider mite Tetranychus telarius. J. Econ. Entomol., 55: 479-483.

Marčić, D.; Ogurlić, I.; Mutavdžić, S. and Perić, P. (2009): The effect of Spiromesifen on the reproductive potential of Tetranychus urticae Koch (Acari: Tetranychidae). Pestic. Phytomed, 24(3): 203-209.

Marei, S.S.; Amr, E.M. and Salem, N.Y. (2009): Effect of some plant oils on biological, physiological and biochemical aspects of Spodoptera littoralis (Boisd). Res. J. Agric. Biol. Sci., 5(1): 103-107.

Miresmailli, S. (2001): Assessing the efficacy and persistence of Rosemary oil-based miticide/insecticide for use on greenhouse Tomato. Master of Science, Faculty of graduate studies, Univ. of British Columbia. pp: 101.

Miresmailli, S. and Isman, M.B. (2006): Efficacy and persistence of Rosemary oil as an acaricide against two-spotted spider mite (Acari: Tetranychidae) on Greenhouse Tomato. J. Econ. Entomol., 99(6): 2015-2023. 
Miresmailli, S.; Bradbury, R. and Isman, M.B. (2006): Comparative toxicity of Rosmarinus officinalis L. essential oil and blends of its major constituents against Tetranychus urticae Koch (Acari: Tetranychidae) on two different host plants. Pest Manag. Sci., 62: 366-371.

Momen, F. M.; Amer, S.A.A. and Refaat, A.M. (2001): Influence of mint and peppermint on Tetranychus urticae and some predacious mites of the family Phytoseiidae (Acari: Tetranychidae: Phytoseiidae). Acta Phytopathol. Entomol. Hung., 36: 143-153.

Nabeta, F.H.; Nakai, M. and Kunimi, Y. (2005): Effects of temperature and photoperiod on the development and reproduction of Adoxophyes honmai (Lepidoptera: Tortricidae). Appl. Entomol. Zool., 40(2): 231-238.

Ogara, E.A.; Hili, D.J. and Maslin, D.J. (2000): Activities of Garlic oil, Garlic powder, and their Diallyl constituents against Helicobacter pylori. Appl. Environ. Microbiol., 66: 2269-2273.

Park, J.H.; Ryu, K.Y.; Lee, B.M. and Jee, H.J. (2008): Effect of COY (Cooking oil and Yolk Mixture) on control of Tetranychus urticae. Korean. J. Appl. Entomol., 47(3):249-254.

Park, Y.L. and Lee, J.H. (2002): Leaf cell and tissue damage of cucumber caused by twospotted spider mite (Acari: Tetranychidae). J. Econ. Entomol., 95: 952-957.

Silva, E.A.; Reis, P.R.; Carvalho, T.M.B. and Altoé, B.F. (2009): Tetranychus urticae (Acari: Tetranychidae) on Gerbera jamesonii Bolus and Hook (Asteraceae). Braz. J. Biol., 69(4): 1121-1125.

Wikipidea, (2011a): Jojoba oil, availble at http://www.wikipedia.org.

Wikipidea, (2011b): Vegetable oils, availble at http://www.wikipedia.org.

Yousri, H. (1987): Toxicological studies on certain acaricides. Ph.D. Thesis, Fac. of Agric., Zagazig Univ., pp: 220.

\section{ARABIC SUMMARY}

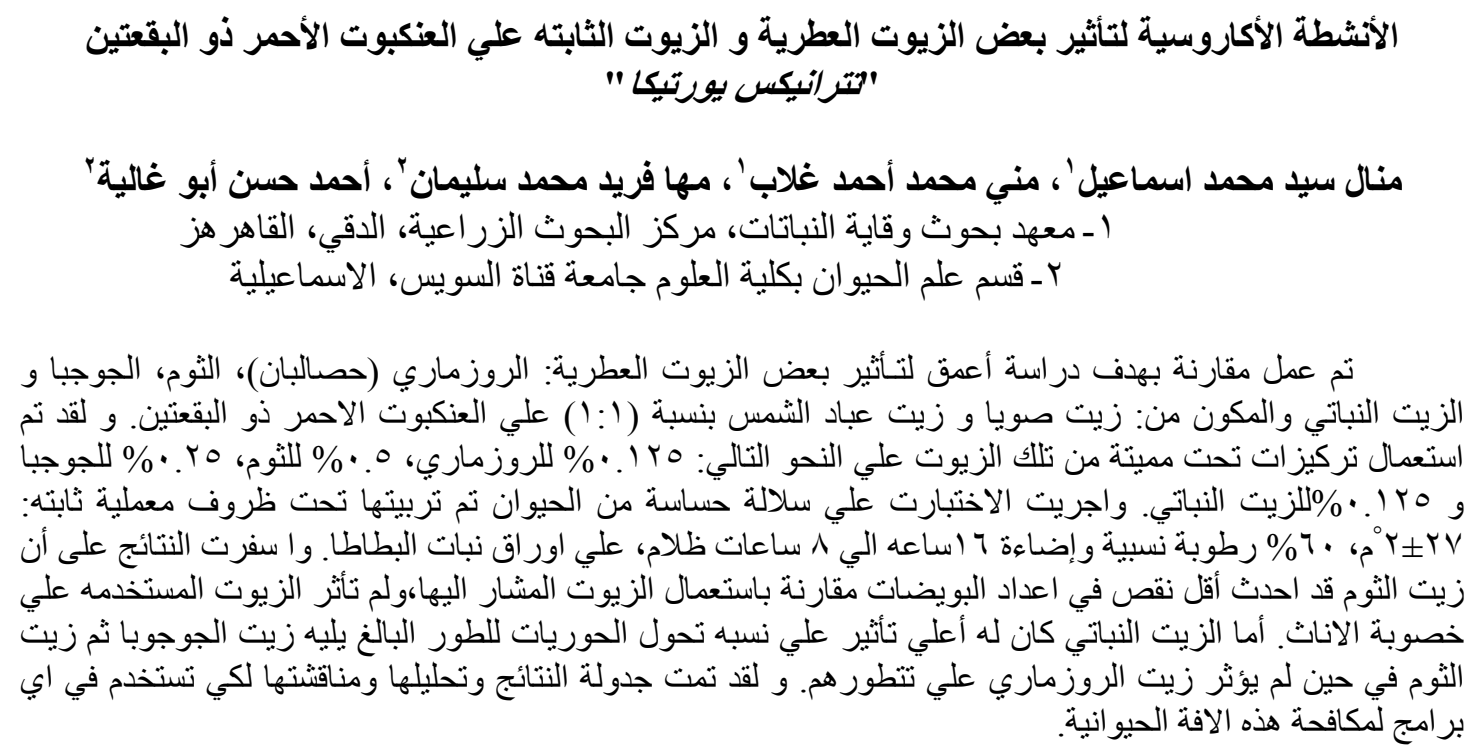

